\title{
Plester sariawan efektif dalam mempercepat penyembuhan stomatitis aftosa rekuren dan ulkus traumatikus
}

\author{
Rahmi Amtha, M. Marcia, Anggia Irma Aninda \\ Departemen IImu Penyakit Mulut, Fakultas Kedokteran Gigi, Universitas Trisakti, Jakarta, Indonesia \\ JI Kyai Tapa 260, Jakarta Barat, Indonesia; e-mail: rahmi.amtha@trisakti.ac.id
}

Submisi: 16 Februari 2017; Penerimaan: 26 April 2017; Publikasi online: 31 Agustus 2017

\begin{abstract}
ABSTRAK
Stomatitis aftosa rekuren (SAR) merupakan salah satu penyakit mulut yang paling umum terjadi. Prevalensi ulserasi mulut di seluruh dunia adalah $4 \%$, dengan SAR menempati urutan terbesar yaitu $25 \%$. Stomatitis aftosa rekuren merupakan ulserasi mulut yang memiliki self-limiting disease, namun sediaan obat yang spesifik untuk mengurangi rasa sakit yang ditimbulkan lesi sampai saat ini masih kurang bervariasi. Penelitian ini bertujuan untuk mengetahui perbedaan efektivitas antara aplikasi topikal asam hialuronat (AH), plester sariawan (PS) serta triamcinolone acetonide 0,1\% (TA) sebagai kontrol positif dalam menyembuhkan SAR dan ulkus traumatikus (UT). Jenis penelitian eksperimental klinis kuasi dengan mengukur diameter lesi serta skala visual analog (VAS) pra dan paska pemberian tiga jenis obat. Hasil uji Kruskal-walis menunjukkan bahwa terdapat perbedaan efektivitas $(p=0,000)$ ketiga jenis obat terhadap penyembuhan SA dan UT. Terdapat perbedaan bermakna penurunan diameter lesi $(p=0,015)$ dan VAS $(p=0,038)$ SAR dan UT dengan penggunaan AH dan PS pada hari ke-4. Tidak ada perbedaan bermakna efektivitas (diameter dan VAS) obat PS dan TA pada hari ke-4 ( $p=0,880$ dan $p=1,000$ secara berurutan). Tidak ada perbedaan bermakna antara masing-masing obat AH, PS dan TA terhadap penyembuhan lesi pada hari ke-7 $(p>0,05)$. Kesimpulan efektivitas PS sama dengan obat topikal yang mengandung kortikosteroid dalam menyembuhkan stomatitis aftosa dan ulkus traumatikus.
\end{abstract}

Kata kunci: asam hialuronat; plester sariawan; stomatitis aftosa; ulkus traumatikus

\begin{abstract}
Mouth ulcer plaster is effective in accelerating the healing of recurrent aphthous stomatitis and traumatic ulcers. Recurrent aphthous stomatitis (RAS) is one of the most commonly occurring oral diseases. The prevalence of oral ulceration worldwide is $4 \%$, with RAS having the largest proportion (25\%). Recurrent aphthous stomatitis is oral ulceration which has a self-limiting disease, but the specific medication to reduce pain caused by lesion is still less varied nowadays. This study aimed to examine the differences in the effectiveness between topical application of hyaluronic acid (HA), mouth ulcer plaster (MUP) and $0.1 \%$ triamcinolone acetonide (TA) as a positive control in the healing of RAS and traumatic ulcers (TU). This was a quasi-experimental study by measuring the lesion diameter as well as visual analogue scale (VAS) pre- and post-administration of three types of medication. Kruskal-walis test results show that there are differences in effectiveness $(p=0.000)$ of the three types of medication to cure RAS and TU. There are significant differences in the reduction of RAS and TU lesion diameter $(p=0.015)$ and VAS $(p=0.038)$ with the use of HA and MUP on the 4th day. There is no significant difference in effectiveness (diameter and VAS) of MUP and TA medication on the fourth day $(p=0.880$ and $p=1.000$ respectively). There is no significant difference among HA, MUP and TA on the healing of the lesions on the seventh day $(p>0.05)$. It can be concluded that the effectiveness of MUP is similar to that of topical medications containing corticosteroids in the healing of RAS and traumatic ulcers.
\end{abstract}

Keywords: hyaluronic acid; mouth oral patch; aphthous stomatitis; traumatic ulcer

\section{PENDAHULUAN}

Penyakit gigi dan mulut merupakan salah satu penyakit yang masih menjadi perhatian di seluruh dunia khususnya di Indonesia. Penyakit mulut yang paling umum terjadi adalah stomatitis aftosa rekuren (SAR) dan ulkus traumatikus, yang biasa dikenal dengan nama sariawan oleh masyarakat awam. Prevalensi ulserasi dalam mulut di seluruh dunia diketahui $4 \%$, dan SAR merupakan penyakit dengan prevalensi terbesar yaitu $25 \%{ }^{1,2}$ Stomatitis aftosa rekuren merupakan penyakit yang menyerang berbagai kalangan usia, baik anak anak, remaja, dewasa, maupun lansia dan sering timbul pada mukosa mulut yang tidak berkeratin. Karakteristik SAR dalam mulut dapat berupa ulkus mayor, minor maupun herpetiformis. Meskipun etiologinya belum diketahui secara jelas, tetapi ada beberapa faktor predisposisi yang sering dikaitkan 
dengan SAR, antara lain trauma, genetik, berhenti merokok, perubahan hormon, stres, dan defisiensi nutrisi. ${ }^{3}$ Demikian pula dengan ulkus traumatikus (UT) yang disebabkan oleh trauma mekanis, sering ditemukan pada praktik sehari-hari.

Berbagai macam obat sering digunakan untuk mengurangi gejala-gejala yang timbul pada SAR dan UT. Pengobatannya pun bervariasi tergantung dari faktor pemicunya. Prinsip dasar pengobatan penyakit mulut antara lain adalah dengan memberikan pengobatan secara simptomatis, mulai dari pemberian obat yang mengandung anestetikum hingga kortikosteroid. Manfaat dari obat - obat tersebut adalah untuk mengurangi reaksi peradangan yang muncul akibat terjadinya kondisi dolor, tumor, calor, rubor, dan functiolasea dan tentu saja akan mempercepat penyembuhan. Gejala yang muncul biasanya berupa rasa sakit, panas dan perih yang amat mengganggu kelancaran aktivitas rongga mulut seperti makan, minum, berbicara bahkan menelan jika lesi muncul pada area sekitar fausea atau lidah. Walaupun dikatakan SAR adalah penyakit yang bisa sembuh sendiri, namun hingga saat ini obat yang spesifik untuk mengurangi rasa sakit yang ditimbulkan masih sangat langka karena umumnya berbentuk salep atau gel yang mudah lepas dari atas lesi. Prinsip dasar covering agent untuk pengobatan lesi dianggap penting untuk membantu menghilangkan rasa sakit yang muncul karena lesi terlindungi oleh segala iritan.

Pengobatan yang efektifuntuk menyembuhkan SAR sangat bervariatif. Salah satu obat yang sering digunakan adalah vitamin $\mathrm{C}$, obat kumur seperti chlorhexidine gluconate $0,2 \%$, obat kumur antibiotika (larutan tetrasiklin 2\%), salep dengan kandungan asam hialuronat (AH), steroid topikal, sampai dengan herbal seperti madu dan lainlain. Asam hialuronat merupakan polimer linear dari asam glukoronik dan $\mathrm{N}$-asetilglukosamin disakarida. Asam hialuronat merupakan matriks ekstraseluler yang dihasilkan tubuh saat terjadi inflamasi akibat jejas jaringan, dan komponen ini merupakan salah satu pengikat yang berfungsi untuk meredakan peradangan. ${ }^{4}$ Pemberian asam hyaluronat gel pada lesi SAR diharapkan proses peradangan yang terjadi dapat segera teratasi. Gel dengan kandungan $\mathrm{AH}$ sudah banyak dipakai dan memberikan kesembuhan berkisar $5-8$ hari tergantung dari jenis SAR dan kepatuhan pasien dalam memakai obat tersebut secara teratur. Sejauh ini gel AH tidak memiliki efek samping secara sistemik sehingga dapat dijadikan salah satu pilihan obat topikal SAR. ${ }^{5}$

Dekade terakhir ini terdapat jenis obat topikal lain yang disebut plester sariawan (PS). Berbeda dengan jenis obat SAR topikal lainnya, obat ini mengangkat konsep proteksi penuh pada lesi (full covering agent) yang memungkinkan lesi untuk terhindar dari iritan dan memberi kesempatan untuk regenerasi atau repitelisasi sel, sehingga memicu terjadinya kesembuhan lesi. Plester sariawan terdiri dari bahan metilselulosa kering (seperti kertas) yang mengandung kalsium dan elemen fosfor yang akan berubah menjadi gel (hidrogel) apabila berkontak dengan saliva. ${ }^{6}$ Kondisi ini memungkinkan lesi untuk lebih cepat sembuh dan yang terpenting mungkin dapat mengurangi keluhan rasa sakit secara signifikan yang menjadi gejala patognomonik lesi SAR dan UT. Penggunaannya di bidang kedokteran gigi dalam hal ini untuk mengatasi keluhan rasa sakit hingga efektivitas penyembuhannya belum banyak diteliti. Berdasarkan latar belakang kedua jenis obat tersebut di atas, maka dianggap perlu untuk dilakukan penelitian untuk mencobakan dua jenis obat tersebut untuk melihat efektivitas keduanya terhadap penyembuhan SAR.

\section{METODE PENELITIAN}

Penelitian ini adalah single blind - randomized clinical trial dengan consecutive sampling dan dilakukan di Departemen IImu Penyakit Mulut, Fakultas Kedokteran Gigi, Universitas Trisakti dan telah mendapatkan persetujuan dari Komite Etik, Fakultas Kedokteran Gigi, Universitas Trisakti dengan nomor surat 312/KE/FKG/03/2016. Kriteria inklusi adalah pasien dengan SAR atau ulkus traumatikus (UT) dan kooperatif dengan pengobatan. Kriteria eksklusi adalah pasien yang telah menerima pengobatan dengan analgesik, pasien dengan penyakit sistemik dan pasien yang sedang menjalani proses kemoterapi 
atau radioterapi. Informed consent tertulis diterapkan untuk semua pasien yang setuju untuk berpartisipasi dalam penelitian ini. Pasien dengan SAR digolongkan secara acak menjadi tiga kelompok berdasarkan perlakuan yang diberikan, yakni kelompok perlakukan dengan asam hialuronat (Grup A), plester sariawan (Grup B) dan kortikosteroid (Grup C) triamcinolone acetonide (TA) sebagai kontrol positif. Parameter proses penyembuhan ditentukan oleh diameter lesi dan rasa sakit yang diukur melalui metode visual analog scale (VAS). ${ }^{3}$ Semua data ini diambil pada kunjungan pertama, kontrol pertama (hari keempat) dan kontrol kedua (hari ketujuh).

Data yang terkumpul dicatat dalam performa Microsoft Excel kemudian dianalisis dengan dimasukkan dalam Statistical Package for Social Sciences (SPSS). Variabel demografik disajikan dalam bentuk frekuensi dan prosentase. Diameter dan variabel VAS disajikan sebagai frekuensi dan rata-rata (mean). Distribusi data rasio diuji dengan Kolmogorof smirnov dan uji beda antar 2 kelompok dilakukan dengan Uji Mann-Whitney dan Kruskallwalis untuk uji antar 3 kelompok.

\section{HASIL PENELITIAN}

Jumlah subjek penelitian yang terkumpul adalah 75 pasien dengan rentang usia bervariatif dari usia anak hingga dewasa. Sosiodemografik subjek penelitian dapat dilihat pada Tabel 1.

Uji normalitas data diameter lesi dan VAS dilakukan dengan Kolmogorof smirnov menunjukkan bahwa data tidak terdistribusi normal $(p=$ $0,00, p<0,05$ ). Perbedaan ketiga kelompok obat kemudian diuji dengan Kruskal-Walis terhadap diameter lesi dan VAS yang dapat dilihat pada Tabel 2. Terdapat perbedaan bermakna antara 3 jenis obat $(A, B$ dan $C)$ terhadap penyembuhan lesi SAR dan UT. Perbedaan efektivitas ketiga jenis obat dapat dilihat pada grafik Gambar 1.

Uji beda Mann-Whitney antar 2 variabel obat menunjukkan efektivitas menyembuhkan lesi, obat $\mathrm{B}$ lebih cepat mengurangi diameter lesi dan mengurangi rasa sakit dibandingkan obat $\mathrm{A}$ pada hari ke-4 dan sama efektivitasnya jika dibandingkan dengan obat $C$ (Tabel 3). Pada hari ke-7 ketiga obat tidak menunjukkan perbedaan dalam hal mengurangi diameter lesi dan rasa sakit (Tabel 4).
Tabel 1. Sosiodemografik subjek penelitian

\begin{tabular}{|c|c|c|c|}
\hline Karakteristik & $\mathbf{N}$ & $\%$ & SD \\
\hline \multicolumn{4}{|l|}{ Umur } \\
\hline $5-15$ tahun & 8 & 10,7 & \\
\hline $16-35$ tahun & 28 & 37,3 & \\
\hline $26-35$ tahun & 15 & 20 & $29.12 \pm 1.302$ \\
\hline $36-45$ tahun & 10 & 13,3 & \\
\hline $46-55$ tahun & 14 & 18,7 & \\
\hline \multicolumn{4}{|l|}{ Jenis Kelamin } \\
\hline Laki-laki & 17 & 22,7 & \\
\hline Perempuan & 58 & 77,3 & \\
\hline \multicolumn{4}{|l|}{ Jenis Lesi } \\
\hline Stomatitis Aftosa & 70 & 93,3 & \\
\hline Ulkus Traumatikus & 5 & 6,7 & \\
\hline \multicolumn{4}{|l|}{ Lokasi Lesi } \\
\hline Lidah & 9 & 12 & \\
\hline Bibir & 36 & 48 & \\
\hline Mukosa Pipi & 10 & 13,3 & \\
\hline Dasar Mulut & 6 & 8 & \\
\hline Palatum & 3 & 4 & \\
\hline Gingiva & 11 & 14,7 & \\
\hline \multicolumn{4}{|l|}{ Pekerjaan } \\
\hline Pelajar/Mahasiswa & 33 & 44 & \\
\hline Ibu Rumah Tangga & 16 & 21,3 & \\
\hline Karyawan & 12 & 16 & \\
\hline Profesional & 12 & 16 & \\
\hline Tidak Bekerja & 2 & 2,7 & \\
\hline
\end{tabular}

Tabel 2. Uji beda kruskal-walis antar diameter lesi dan VAS

\begin{tabular}{|c|c|c|c|c|}
\hline & Grup & $\mathrm{N}$ & Mean Rank & $\begin{array}{l}\text { Chi-Square } \\
\mathrm{P} \text { value }\end{array}$ \\
\hline \multirow[t]{10}{*}{ Diameter Lesi } & $1 \mathrm{~A}$ & 35 & 155,21 & \\
\hline & 1B & 30 & 157,02 & \\
\hline & $1 \mathrm{C}$ & 10 & 163,15 & \\
\hline & $2 \mathrm{~A}$ & 35 & 137,23 & 0,00 \\
\hline & $2 \mathrm{~B}$ & 30 & 98,07 & \\
\hline & $2 \mathrm{C}$ & 10 & 131,90 & \\
\hline & $3 A$ & 35 & 76,40 & \\
\hline & $3 B$ & 30 & 46,87 & \\
\hline & $3 C$ & 10 & 50,65 & \\
\hline & Total & 225 & & \\
\hline \multirow[t]{10}{*}{ VAS } & $1 \mathrm{~A}$ & 35 & 179,36 & \\
\hline & $1 \mathrm{~B}$ & 30 & 189,73 & \\
\hline & $1 \mathrm{C}$ & 10 & 183,50 & \\
\hline & $2 \mathrm{~A}$ & 35 & 108,39 & 0,00 \\
\hline & $2 \mathrm{~B}$ & 30 & 84,93 & \\
\hline & $2 \mathrm{C}$ & 10 & 79,75 & \\
\hline & $3 A$ & 35 & 65,19 & \\
\hline & $3 B$ & 30 & 55,00 & \\
\hline & $3 C$ & 10 & 55,00 & \\
\hline & Total & 225 & & \\
\hline
\end{tabular}

1A / 1B / 1C: Grup A / B / C kunjungan pertama 2A / 2B / 2C: Grup A / B / C kontrol hari ke-4 3A / 3B / 3C: Grup A / B / C kontrol hari ke-7 


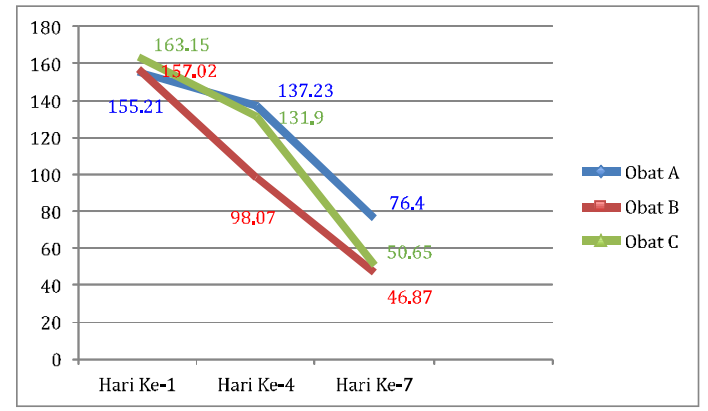

Diameter lesi

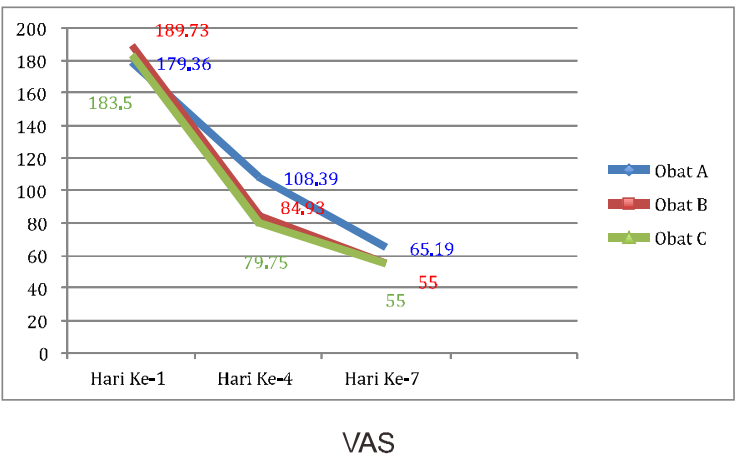

VAS

Gambar 1. Perbedaan efektivitas obat A, obat B dan obat C berdasarkan diameter lesi (A) dan VAS (B)

Tabel 3. Perbedaan antar 2 jenis obat pada hari ke-empat

\begin{tabular}{cllcl}
\hline Jenis obat & Obat & $\mathbf{N}$ & Rata-rata & P Value \\
\hline \multirow{2}{*}{ Diameter Lesi } & Obat A & 35 & 23,30 & \multirow{2}{*}{0,773} \\
& Obat C & 10 & 21,95 & \\
VAS & Obat A & 35 & 24,61 & 0,106 \\
Diameter Lesi & Obat C & 10 & 17,35 & \\
& Obat A & 35 & 38,24 & $\mathbf{0 , 0 1 5 ^ { * }}$ \\
& Obat B & 30 & 26,88 & \\
VAS & Obat A & 35 & 37,23 & $\mathbf{0 , 0 3 \mathbf { 0 } ^ { * }}$ \\
& Obat B & 30 & 28,07 & \\
\multirow{4}{*}{ VAS } & Obat B & 30 & 18,95 & 0,140 \\
& Obat C & 10 & 25,15 & \\
& Obat B & 30 & 20,82 & 0,726 \\
& Obat C & 10 & 19,55 & \\
\hline
\end{tabular}

${ }^{*} \mathrm{p}<0.005$

Tabel 4. Perbedaan antar 2 jenis obat pada hari ke-tujuh

\begin{tabular}{cllcc}
\hline & Obat & $\mathbf{N}$ & Rata-rata & P Value \\
\hline \multirow{2}{*}{ Diameter Lesi } & Obat A & 35 & 36,77 & \multirow{2}{*}{0,052} \\
& Obat B & 30 & 28,60 & \\
VAS & Obat A & 35 & 34,71 & 0,058 \\
Diameter Lesi & Obat B & 30 & 31,00 & \\
& Obat A & 35 & 24,17 & 0,274 \\
& Obat C & 10 & 18,90 & \\
VAS & Obat A & 35 & 23,57 & 0,600 \\
& Obat C & 10 & 21,00 & \\
Diameter Lesi & Obat B & 30 & 20,37 & 0,880 \\
& Obat C & 10 & 20,90 & \\
VAS & Obat B & 30 & 20,50 & 1,000 \\
& Obat C & 10 & 20,50 & \\
\hline
\end{tabular}

\section{PEMBAHASAN}

Pada studi ini tampak sebagian besar $(57,5 \%)$ usia yang terserang stomatitis aftosa rekuren (SAR) adalah wanita pada usia remaja ( $16-25$ tahun) dan dewasa muda ( 26 - 35 tahun) dan semakin rendah angka kejadiannya seiring dengan bertambahnya usia. Wanita usia remaja dan dewasa muda diasumsikan sebagai usia yang banyak terpapar pada berbagai faktor psikologis, hormonal, beban kerja yang tinggi dan trauma. Hal ini sesuai dengan banyak gambaran prevalensi SAR di seluruh pelosok dunia yang menyatakan angka kejadian SAR menurun sesuai dengan bertambahnya usia. ${ }^{7,8,9}$ Berkurangnya jumlah penderita SAR sesuai dengan pertambahan usia dibandingkan usia muda berkaitan erat dengan sistem imun yang diketahui memiliki hubungan dengan etiopatogenesis dari stomatitis aphtosa. Penurunan angka kejadian seiring bertambahnya usia, sebagian tergantung pada bawaan (innate) tubuh dan komponen adaptif tubuh yang digambarkan sebagai "inflam aging" (penuaan komponen radang). Hal ini menyebabkan berkurangnya respon tubuh terhadap komponen yang dapat memicu terjadinya reaksi imun dan menyebabkan lepasnya sitokin pro inflamasi (Th 1) maupun sitokin pro anti inflamasi (Th 2) sehingga tidak menyerang sel epitel mukosa mulut. ${ }^{10}$

Lesi jenis SAR lebih banyak ditemukan pada rongga mulut dibandingkan ulkus traumatikus (UT). Hal ini berdasarkan riwayat terjadinya dan gambaran klinis lesi. Lesi dengan pinggiran lesi yang teratur dan dikelilingi daerah kemerahan serta dasar lesi ditutupi oleh fibrin berwarna putih kekuningan biasanya terjadi akibat adanya trauma atau dengan faktor yang lain dan melibatkan mediator kimia / sitokin sehingga memicu terjadinya reaksi sitotoksik (imunologis) yang berujung pada rusaknya epitel mukosa, sedangkan UT terjadi apabila epitel mukosa mulut rusak akibat adanya jejas akut dan hanya melibatkan sel radang akut dengan gambaran klinis terlihat tepi lesi yang tidak teratur. Namun kedua lesi secara klinis 
oleh masyarakat awam sering dianggap sebagai sariawan.

Pada lesi yang masuk dalam penelitian ini dipastikan tidak ada yang dilatarbelakangi oleh penyakit sistemik. Sesuai dengan hasil penelitian yang dilakukan oleh Scully dan Poter tahun 2008 yang menunjukkan bahwa SAR dengan latar belakang sistemik seperti gangguan gastrointestinal dan defisiensi mikro elemen biasanya akan bersifat rekuren dan kesembuhannya dipengaruhi oleh dapat atau tidaknya pengendalian faktor sistemiknya sehingga pengukuran efektivitas obat yang bersifat simptomatik tidak dapat diukur secara langsung karena melibatkan mekanisme penyembuhan secara sistemiknya. ${ }^{11}$

Sebagian besar pekerjaan subjek penelitian adalah pelajar/mahasiswa, diikuti dengan para karyawan dan kaum profesional serta ibu rumah tangga. Anamnesis tampak sebagian besar subjek merupakan subjek yang punya kesibukan. Ibu rumah tangga memiliki serangkaian pekerjaan rumah yang amat menyita perhatian dan tenaga. Hal ini sesuai dengan gambaran sosiodemografi SAR pada seluruh populasi di dunia. Stomatitis aphtosa yang timbul umumnya berhubungan dengan pekerjaan yang menyebabkan tekanan psikologis yang dapat terjadi pada semua kalangan usia. $^{12}$

Lokasi lesi yang paling banyak timbul lesi pada penelitian ini adalah daerah bibir dan mukosa pipi. Kedua predileksi lesi tersebut menunjukkan karakteristik tempat yang kerap terserang SAR dan UT. Hal ini karena SAR yang bukan jenis rekuren paling sering terjadi karena tergigit saat bicara atau makan dan bibir serta mukosa mulut merupakan lokasi paling luar yang berhadapan dengan gigi geligi. Demikian halnya dengan gingiva yang sering terkena iritasi atau trauma saat menyikat gigi. Hal ini sejalan dengan yang pernah dikemukakan oleh Jurge dkk bahwa trauma pada mukosa mulut dapat disebabkan oleh injeksi anestesi lokal, bentuk gigi yang tajam, perawatan gigi, dan luka akibat sikat gigi dapat menjadi faktor pendukung pada perkembangan SAR. ${ }^{13}$

Secara garis besar, terdapat perbedaan efektivitas antara penggunaan gel asam hyaluronat
$(\mathrm{AH})$, plester sariawan (PS) dan pasta kortikosteroid triamcinolone acetonide (TA). Pada Gambar 1(A) tampak obat B (PS) menunjukkan penurunan diameter lesi berjalan linear ke bawah secara signifikan yaitu setengah dari ukuran lesi setiap kali subjek kontrol (hari ke-4 dan ke 7) sedangkan obat $A$ (AH) dan C (TA) menunjukkan perlambatan respon penurunan diameter lesi pada hari ke-4 namun kemudian turun cukup cepat setelah hari ke-4 hingga ke-7. Pada Gambar 1(B) tampak penurunan rasa sakit yang sama antara obat $B$ dan $C$ hingga hari ke-7, sedangkan obat $A$ tampak sedikit lebih lambat dalam hal mengurangi rasa sakit pada hari ke-1 hingga 4. Hal ini karena AH yang merupakan komponen karbohidrat utama pada matriks ekstra seluluer berperan dalam mengendalikan hidrasi jaringan selama periode perubahan epitel seperti akibat proses inflamasi atau respons terhadap cedera jaringan. Asam hyaluronat juga memiliki properti khusus untuk meningkatkan proliferasi dan migrasi sel, dengan menurunkan perlekatan antar sel radang pada matriks ekstraseluler sehingga memungkinkan terjadinya migrasi sel. Pada kondisi radang, $\mathrm{AH}$ dapat memobilisasi molekul air yang terkumpul dan menyebabkan berkurangnya peradangan. Selain itu, AH juga memiliki efek yang cukup kuat dalam hal mencegah radikal bebas, efek antioksidan, serta melalui enzim pada jaringan yang berasal dari lingkungan selular atau komponen struktural lainnya dari matriks ekstraseluler dan meningaktkan angiogenesis sehingga oksigen mengalir baik ke jaringan. Semua sifat tersebut cenderung untuk berkontribusi pada proses penyembuhan lesi. ${ }^{14}$ Namun dengan adanya jejas yang menyebabkan rusaknya epitel (secara klinis SAR dan UT), diperlukan kontak AH pada jaringan dalam waktu yang lebih lama. Hal ini dimaksudkan agar memberikan kesempatan molekul $\mathrm{AH}$ untuk diserap dan melakukan aktivitas anti inflamasi dengan sempurna. Dalam hal ini sifat covering agent sebagai prinsip dasar penyembuhan luka amat diperlukan sehingga memberikan kesempatan bagi sel epitel untuk beregenerasi dan sembuh. Pada preparat gel diketahui komposisi air lebih banyak dibandingkan dengan jenis pasta atau plester.

Obat C yang berupa pasta kortikosteroid triamcinolone acetonide $0,1 \%$ adalah jenis orabase 
yang mempunyai kemampuan untuk melekat pada mukosa mulut yang secara alami bersifat lembab dan berlendir karena terdapat saliva. Obat $C$ dianggap obat baku untuk penyembuhan SAR, karena daya proteksi (covering agent) dan sifat anti radangnya yang potensial. Sifat proteksi kuat juga di dapat dari jenis obat $B$ yang merupakan jenis plester. Plester sariawan (PS) yang berasal dari bahan metil selulosa dengan kandungan kalsium akan berubah menjadi hidrogel yang lebih kuat melekat pada mukosa mulut dengan bantuan saliva. Selain itu kalsium yang terkandung pada PS akan memblok calcium chanel sehingga mampu mengurangi rasa sakit yang disebabkan karena lepasnya sitokin pro inflamasi (Th 1) maupun sitokin pro anti inflamasi (Th 2) sebagai akibat jejas atau faktor penyebab lainnya.

Pada hari ke-4, PS tampak lebih cepat menurunkan ukuran lesi dan mengurangi rasa sakit jika dibandingkan obat yang mengandung $\mathrm{AH}$. Hal ini mungkin dilatarbelakangi oleh kemampuan $\mathrm{AH}$ dalam mengendalikan produk radang cukup kuat akan tetapi lesi tidak cukup terlindungi sehingga jejas pada lesi selama makan, minum dan berbicara masih tetap terjadi. Pada hari ke-7 tampak ke tiga jenis obat tidak berbeda bermakna dalam hal menyembuhkan lesi. Hal ini menunjukkan proses radang sebagian besar dapat diatasi oleh ketiganya dalam kurun waktu kurang dari 7 hari. Namun apabila dilihat dari rata-rata lamanya penyembuhan, obat dengan golongan kortikosteroid lebih cepat mengatasi radang dan menyembuhkan lesi dibandingkan obat golongan $\mathrm{AH}$ atau PS. Hal ini sesuai dengan berbagai penelitian yang menunjukkan bahwa kortikosteroid memiliki efek anti-inflamasi yang kuat, karena mampu menurunkan jumlah dan fungsi berbagai sel imun, seperti $T$ dan $B$ limfosit, monosit, neutrofil, dan eosinofil, pada lokasi inflamasi. ${ }^{15}$ Kortikosteroid menurunkan produksi sitokin, kemokin, dan eikosanoid serta meningkatkan produksi makrofag yang menghambat migrasi sel. ${ }^{15}$ Selain sebagai bahan aktif utama, kortikosteroid juga berada dalam wadah orabase yang amat baik, sehingga memberikan kesempatan bahan aktif tersebut berkontak dan melindungi lesi dari jejas luar dan akhirnya dapat terserap dengan baik. Kortikosteorid memiliki beberapa golongan berdasarkan kemampuannya (potensi). Pada penelitian ini digunakan yang jenis triamcinolone acetonid $0,1 \%$ yang merupakan jenis paling lemah untuk mencegah beberapa efek samping seperti kandidiasis akibat pemakaian topikal yang kurang benar dan jangka waktu yang lama.

\section{KESIMPULAN}

Hasil penelitian ini menunjukkan bahwa terdapat perbedaan bermakna antara penggunaan tiga jenis obat yang mengandung asam hyaluronat, plester sariawan dan pasta kortikosteroid triamcinolone acetonide $0,1 \%$ (sebagai kontrol positif) terhadap efektivitas penyembuhan stomatitis aftosa dan ulkus traumatikus. Plester sariawan efektif mengurangi rasa sakit dan ukuran lesi pada hari ke-4 setara dengan pasta yang mengandung kortikosteroid dan tidak berbeda dengan dua obat lainnya pada hari ke-7. Berdasarkan penelitian ini maka diperlukan dilakukan penelitian lebih lanjut yang lebih luas berdasarkan community-base sehingga dapat menjadi salah satu alternatif pemilihan obat stomatitis aftosa yang bersifat simptomatik yang dapat dibeli bebas oleh masyarakat.

\section{UCAPAN TERIMA KASIH}

Peneliti ingin mengucapkan terima kasih kepada staf Departemen IImu Penyakit Mulut, Fakultas Kedokteran Gigi, Universitas Trisakti, drg.Widijanto Sudhana, M.Kes., untuk analisis statistik serta PT. Kolosal Pratama atas dukungannya dalam penelitian ini.

\section{DAFTAR PUSTAKA}

1. Chavan M, Jain H, Diwan H, Khedkar S, Shete A, Durkar S. Recurrent aphthous stomatitis: a review. J Oral Pathol Med. 2012; 41: 577 583.

2. Scully $\mathrm{C}$, Porter $\mathrm{S}$. Oral mucosal disease: recurrent aphthous stomatitis. $\mathrm{Br} J$ Oral Maxillofac Surg. 2008; 46: 198 - 206.

3. Preeti L, Magesh KT, Rajkumar K, Karthik R. Recurrent apthous stomatitis. J Oralmaxillofac Pathol. 2011; 15(3): 252 - 256. 
4. Belenguer-Guallar I, Jiménez-Soriano $\mathrm{Y}$, Claramunt-Lozano A. Treatment of recurrent aphthous stomatitis. A literature review. Journal of Clinical and Experimental Dentistry. 2014; 6(2): e168 -e174. doi:10.4317/jced.51401

5. Koray M, Ofluoglu D, Senemtasi A, İşsever $H$, Yaltirik M. The efficacy of hyaluronic acid gel in pain control of recurrent aphthous stomatitis. Int J Dentistry Oral Sci. 2016; 3(6): 273 - 275.

6. Zhou DZ. Ulceloocin oral ulcer patch summary report of clinical trial. school of Dentistry, Shanghai Jiaotong University, Department of Oral Medicine. Reseacrh report fliers; 2011.

8. McCullough MJ, Abdel-Hafeth S, Scully C. Recurrent aphthous stomatitis revisited; clinical features, associations, and new association with infant feeding practices?. J Oral Pathol Med. 2007; 36: 615 - 620.

9. Reichart PA. Oral mucosal lesions in a representative cross-sectional study of aging Germans. Community Dent Oral Epidemiol. 2000; 28: 390 - 398.

10. Wolach B, Gavrieli R, Roos D, Berger-Achituv $S$. Lessons learned from phagocytic function studies in a large cohort of patients with recurrent infections. J Clin Immunol. 2012; 32: $454-466$.
11. Maheaswari R, Priyadharshini V, Gaurav A. Is immunesenescence a contributing factor for periodontal diseases. J Indian Soc Periodontol. 2013; 17: 169 - 174.

12. Porter S, Scully C. Aphthous ulcers (recurrent). Clin Evid. 2005; 13: 1687 - 1694.

13. Gallo Cde B, Mimura MA, Sugaya NN. Psychological stress and recurrent aphthous stomatitis. Clinics (Sao Paulo). 2009; 64: 645 -648 .

14. Jurge S, Kuffer R, Scully C, Porter SR. Mucosal disease series. Number VI. Recurrent aphthous stomatitis. Oral Dis. 2006; 12(1): 1 21.

15. Nolan A, Baillie C, Badminton J, Rudralingham $M$, Seymour RA. The efficacy of topical hyaluronic acid in the management of recurrent aphthous ulceration. J Oral Pathol Med. 2006; 35: $461-465$.

16. Gibson N, Ferguson JW. Steroid cover for dental patients on long-term steroid medication: proposed clinical guidelines based upon a critical review of the literature. BDJ. 2004; 197(11): $681-685$. 